\title{
Ein neues Bild Franz Anton Mesmers
}

Von Alfred G. Roth, Burgdorf

Vor Jahren erhielt der Rittersaalverein Burgdorf von August Franz Strommayer (1849-1925) das Pastellbild des Dr. med. Franz Anton Mesmer geschenkt. Strommayer war der Sohn des Franz Anton Strommayer (1806-1897), der 1857 Burger zu Burgdorf geworden war und dessen Vater Dr. med. Franz Xaver Strommayer (1768-1814) Neffe des Dargestellten gewesen ist. Von Franz Xaver besitzt der Rittersaalverein das am 12. September 1793 in Freiburg i. Br. ausgestellte Doktordiplom.

Das Porträt hat die Maße von $40 \times 49 \mathrm{~cm}$ im Rahmen. In Lebensgröße, genau im Profil und doch plastisch modelliert, ist Mesmer dargestellt. Das glattrasierte Gesicht zeigt eine warme, gesunde Farbe; Lippen, Nase und Lider sind stark rot gehöht. Die gepuderten Haare werden in einem grauschwarzen, bemaschten Zopfbeutel zusammengehalten. Ein feines weißes Jabot wird leicht angedeutet, der dunkelgraue Rock und der braungraue Hintergrund sind nur als Folie behandelt. Als einziger schwarzer Fleck, als der stärkste Punkt wirkt das Auge (im Original mehr als in der Abbildung).

Das Burgdorfer Bild unterscheidet sich bedeutsam von den sonst bekannten Bildnissen Mesmers, etwa dem hausbackenen im Kernermuseum zu Weinsberg oder dem trockenen Stich von Meyer in Wolfarts "Mesmerismus» 1814. Es darf am ersten den Vergleich mit der äußeren Beschreibung Mesmers aushalten, wie sie etwa René Kaech gibt (CibaZeitschrift 1947, S. 3828): "Er ist groß und von sehr elegantem, einnehmendem Äußeren; im besten Alter stehend, ist er noch im Besitz seiner Jugendkraft. Seine Ruhe, seine Heiterkeit und sein inneres Gleichgewicht teilen sich der Umgebung mit, während von seinen Augen eine faszinierende Wirkung ausgeht. Bei einem neugierigen, schnell gewonnenen Publikum hat er keine Schwierigkeiten, seine Patienten in einen hypnotischen Zustand zu versetzen, in dem sie therapeutischen Suggestionen zugänglich sind. Während er seine Erfolge einem magnetischen Fluidum zuschrieb, sind sie, und das hat er selbst nie erkannt, aus Suggestion und Hypnose zu erklären.» Aus dem Burgdorfer Bilde kann die geschilderte Wirkung auf die Patienten am ehesten verstanden werden.

Auf Grund dieser Feststellungen kann kein Zweifel sein - und die malerische Qualität bestätigt das —, daß der Porträtist ein hervorragender Künstler gewesen sein muß. Leider hat er das Bild weder signiert 
noch datiert. Wir möchten ihn am ehesten in Paris suchen. Mesmer hat unter zwei Malen dort geweilt, in den 1780er Jahren und um 1800. Auf Grund des Alters des Dargestellten und auf Grund stilkritischer Anhaltspunkte - Louis XVI. - möchten wir das Bild der Zeit kurz vor der großen Revolution zuschreiben, doch welchem Maler, bleibe dahingestellt. Die Kunst, mit welcher das Auge, die Haare, das zarte Jabot wiedergegeben sind, lassen auf einen Meister im Pastellfach schließen.

Der Rittersaalverein Burgdorf freut sich, sowohl was die Person des Dargestellten als auch was die Kunst der Darstellung betrifft, ein Bild von solcher Qualität zu besitzen und Gelegenheit zu finden, es gebührend publizieren zu dürfen.

\section{Empiristische Grundlagen \\ der chemischen Theorie in der ersten Hälfte des I9. Jahrhunderts}

(Abhandlungen zur theoretischen Wissenschaftsgeschichte II)

Von Emil J. Walter, Zürich

\section{$\S 1$. Problemstellung}

Die vorliegende Studie behandelt einige Probleme, die sich uns beim nähern Studium der Vorgeschichte der chemischen Valenzlehre ergaben. In der Gegenwart ist mit der Physik der Elektronenhülle der Atome die chemische Valenzlehre, deren Anfänge bis in die erste Hälfte des 19. Jahrhunderts zurückreichen, zu einem prinzipiellen Abschlusse gelangt. Vom modernen Standpunkte aus erscheinen manche Schwierigkeiten der chemischen Theorie aus der Zeit vor der Formulierung der Valenzlehre in den sechziger Jahren des vorigen Jahrhunderts und der Aufstellung des periodischen Systems der Elemente zu Beginn der siebziger Jahre in einem neuen Lichte. Die vier großen Klassen der Stoffe, die salzartigen, die metallischen, die diamantähnlichen und die leichtflüchtigen entsprechen grob betrachtet den vier Bindungstypen der modernen Valenzlehre ${ }^{1}$.

1 Siehe: Emil J. Walter, Erforschte Welt, S. 300 ff.; H. Mohler, Elektronentheorie der Chemie, Verlag H. R. Sauerländer \& Co, Aarau 1947; G. Schwarzenbach, Grundriß der allgemeinen und anorganischen Chemie, 2. Auflage 1944, Leipzig. Die auf der 